\title{
La accesibilidad como un nuevo derecho de la personalidad en Brasil: el Estatuto de la Persona con Discapacidad (ley 13.146/2015) y el daño moral que surge de la inaccesibilidad \\ Accessibility as a New Personality Right in Brazil: the \\ Disabled Person Statute (Law 13.146/2015) and the Moral Damage Arising from Inaccessibility
}

\author{
GILBERTO FACHETTI SILVESTRE* \\ Universidade Federal do Espírito Santo (UFES) - Brasil
}

\section{CAMILA VILLA NOVA RAMALHO** \\ Universidade Federal do Espírito Santo (UFES) - Brasil}

\section{DAVI AMARAL HIBNER*** \\ Universidade Federal do Espírito Santo (UFES) - Brasil}

Resumen: El artículo estudia algunos de los cambios producidos a partir de la entrada en vigencia de la ley 13.146/2015 (Estatuto de la Persona con Discapacidad). La ley comentada generó diversas alteraciones en el Código Civil brasileño, con el fin de considerar a la persona con deficiencia plenamente capaz para ejercer todos los actos de la vida civil y, así, protegerla por medio de la libertad a ella concedida. El presente estudio aborda la construcción histórica del tratamiento de la persona con deficiencia y tiene como enfoque principal la accesibilidad como derecho de la personalidad. Así, busca demostrar que la inaccesibilidad genera daño moral y permite la debida reparación civil. En la parte final, se ofrecen ejemplos para ilustrar lo afirmado.

Palabras clave: Estatuto de la Persona con Discapacidad, dignidad humana, derechos de la personalidad, accesibilidad, daño moral

Abstract: The purpose of this paper is to study the changes brought by law 13.146/2015 (Disabled Person Statute), focusing on the issue of moral damages due to inaccessibility. The law in question has brought a number of amendments to the Civil Code in order to consider the person with disabilities fully capable of exercising all acts of civil life; the law protects these people through the freedom granted to them. The present study starts with the historical evolution of the treatment given to the disabled person and has

* Gilberto Fachetti Silvestre es profesor de la Universidade Federal do Espírito Santo (UFES), Brasil; Doctor en Derecho Civil por la Pontifícia Universidade Católica de São Paulo (PUC/SP); Magíster en Derecho Procesal Civil por la Universidade Federal do Espírito Santo (UFES); Abogado. Código ORCID: 0000-0003-3604-7348. Correo electrónico: gilberto.silvestre@ufes.br

* Academia de Derecho - Universidade Federal do Espírito Santo (UFES), Brasil. Código ORCID: 0000-0003-0629-5551. Correo electrónico: cvn.ramalho@gmail.com

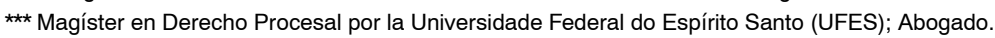
Código ORCID: 0000-0002-3222-3570. Correo electrónico: davi.hibner@alveshibner.adv.br 
as its main focus the accessibility as a personality right. Therefore, it seeks to demonstrate that inaccessibility causes moral damage and leads to adequate civil reparation. Finally, some examples are presented.

Key words: Disabled Person Statute, human dignity, personality rights, accessibility, moral damage

CONTENIDO: I. INTRODUCCIÓN.- II. ACCESIBILIDAD: CONSTRUCCIÓN HISTÓRICA.- III. LA ACCESIBILIDAD COMODERECHO DE LA PERSONALIDAD.IV. EL DAÑO MORAL COMO CONSECUENCIA DE LA INACCESIBILIDAD.- V. EL RESPONSABLE DE LA INDEMNIZACIÓN.- VI. CONCLUSIÓN.

\section{INTRODUCCIÓN}

En el Brasil viven actualmente más de 45 millones de personas con algún tipo de discapacidad, según el censo del Instituto Brasilero de Geografía y Estadística (IBGE) de 2010 (Jaques, s.f.). En este contexto, considerando los principios fundamentales de la Constitución de la República Federativa de Brasil, en especial el principio de igualdad, se hace necesaria la protección de esas personas para que puedan ejercer su ciudadanía y vivir socialmente en igualdad de condiciones con los demás individuos.

A lo largo de los años, diversas leyes fueron creadas, principalmente después de la Constitución Federal de 1988 (CF), con el objetivo de permitir esa inclusión. La más reciente de ellas es la ley 13.146/2015 (Ley Brasilera de Inclusión de la Persona con Discapacidad). Esta, más conocida como Estatuto de la Persona con Discapacidad, regula la Convención sobre los Derechos de las Personas con Discapacidad y su Protocolo Facultativo, ratificados por el Congreso Nacional en 2008 , pasando a tener vigencia internamente en 2009, con fuerza de enmienda a la Constitución.

El Estatuto trae un nuevo enfoque sobre las personas con discapacidad, con el fin de incluirlas en la sociedad como plenamente capaces civilmente, pudiendo ejercer libremente cualquier acto de la vida civil, sea económico, familiar, personal o negociable, conforme se extrae del artículo 6to de dicha ley.

El nuevo tratamiento se basa en la idea de que las personas con discapacidad deben tener su dignidad tutelada por medio de la libertad de practicar cualquier acto en igualdad de condiciones con las demás personas. Este nuevo tratamiento generó una divergencia de opiniones entre los doctores, ya que parte de ellos concuerda con esta protección de la persona con discapacidad por medio de la libertad, mientras que otra parte considera algunas alteraciones perjudiciales. Para esta segunda corriente, las personas con discapacidad deberían ser resguardadas, pues 
asume que son vulnerables, al contrario de lo que ocurrió en el Estatuto (Tartuce, 2015).

No se puede negar, sin embargo, que los avances en lo que se refiere a la positivización de derechos de las personas con discapacidad han sido bastantes, estableciendo diversas normas sobre los derechos fundamentales y, además, poniendo a disposición todo un título (Título III) específico para tratar el derecho a la accesibilidad.

El presente trabajo pretende demostrar que la accesibilidad fue abordada en la ley en cuestión como un derecho de la personalidad y que la ley tiene como fin cumplir el propósito del artículo 5 de la CF, el cual afirma la igualdad entre todas las personas, sin ningún tipo de discriminación. En ese sentido, se realizará inicialmente un análisis general sobre la evolución en el tratamiento de las personas con discapacidad, demostrando los avances legislativos en busca de la protección de las mismas hasta llegar al advenimiento del Estatuto de la Persona con Discapacidad. Luego, se pasará al análisis detenido sobre el derecho a la accesibilidad. Por último, se buscará comprender las circunstancias capaces de generar el deber de indemnizar en razón de la inaccesibilidad.

Para llegar a las debidas conclusiones sobre el tema estudiado, se realizará una investigación bibliográfica con el objetivo de buscar comprender los derechos de la personalidad de forma amplia, concediendo, así, sustentación teórica al presente artículo. Además, se busca confirmar la inclusión de la accesibilidad como derecho de la personalidad también por medio de una investigación de juzgados que demuestre, a partir de casos concretos, de qué modo el tema viene siendo abordado por los tribunales brasileños, comprobándose, así, la tesis de que la inaccesibilidad puede llevar a la indemnización por daños morales.

\section{ACCESIBILIDAD: CONSTRUCCIÓN HISTÓRICA}

El trato dispensado a las personas con discapacidad no siempre gozó de protección; por el contrario, en los inicios de la civilización, tales personas eran tratadas con desprecio. En la Antigua Grecia, había leyes que permitían la eliminación o segregación de las personas con discapacidad; también en Roma, el ordenamiento jurídico permitía la eliminación de los niños que poseían deformidades aparentes (Jaques, s.f.).

Esta práctica de eliminación y segregación de personas con discapacidad ha perdurado por muchos siglos, pasando por la Edad Media y la Edad Moderna sin muchas alteraciones. La ausencia de cualquier respeto hacia las personas con discapacidad puede ser verificada, incluso, por

LA ACCESIBILIDAD COMO UN NUEVO DERECHO DE LA PERSONALIDAD EN BRASIL: EL ESTATUTO DE LA PERSONA CON DISCAPACIDAD (LEY 13.146/2015) Y EL DAÑO MORAL QUE SURGE DE LA INACCESIBILIDAD

ACCESSIBILITY AS A NEW PERSONALITY RIGHT IN BRAZIL:

THE DISABLED PERSON STATUTE (LAW 13.146/2015) AND THE MORAL DAMAGE ARISING FROM INACCESSIBILITY 
las nomenclaturas utilizadas para describirlas, pues se las denomina «disformes» $\mathrm{O}$ «monstruosas».

Con el surgimiento de los ideales de libertad, igualdad, fraternidad y solidaridad en la Revolución Francesa, las personas con discapacidad pasaron a tener espacio en las discusiones sociales. De este modo, se inició la búsqueda de la inclusión de las mismas y del reconocimiento de sus derechos fundamentales. Este proceso no es rápido y se extiende hasta los días actuales; aun así, no se puede afirmar que se encuentra consolidado (Jaques, s.f.). En el siglo XX, principalmente después de la Segunda Guerra Mundial, la preocupación por la inclusión mencionada comenzó a ampliarse, porque las guerras mundiales dejaron como herencia a muchos sobrevivientes con secuelas físicas y psíquicas, surgiendo así la necesidad de rehabilitarlos (Nishiyama \& Teixeira, 2016).

Los cambios fueron progresivos. En principio, se creó la Organización Internacional del Trabajo (OIT), la cual buscaba, entre otras, las mejoras en las condiciones de trabajo de las personas con discapacidad. En 1975, se firmó la Declaración de los Derechos de la Persona con Discapacidad, por medio de la Resolución de la ONU 2542, documento que busca asegurar la implantación de políticas públicas y económicas y que tenía en cuenta las posibles discapacidades de la persona humana (Jaques, s.f.). Más tarde, en 1982, la ONU aprobó el Programa de Acción Mundial para las Personas con Discapacidad. Se puede decir que fue a partir de entonces que tuvo lugar una evolución más marcada en la búsqueda de los derechos de esas personas. Este programa estableció una serie de medidas para promover la reforma de la sociedad con el fin de incluir a las personas con discapacidad, posibilitando una participación plena, a fin de superar las barreras físicas y sociales que se les imponían (Pereira \& Lelis, 2016).

En el ámbito nacional, las constituciones anteriores a la Constitución de la República Federativa de Brasil de 1988 contienen muy pocas disposiciones acerca de las personas con discapacidad. La primera mención solo ocurrió en la Constitución de 1967, con la enmienda constitucional 01 y, aun así, no había mucha efectividad práctica en las disposiciones. Fue la Carta Magna de 1988 la que pasó a abordar cambios más relevantes sobre los derechos y garantías de las personas con discapacidad (Jaques, s.f.).

En este sentido, en la Constitución de la República Federativa de Brasil de 1988 se nota una preocupación mucho mayor con respecto a las personas con discapacidades. No hay un capítulo o título exclusivo para tratar sus derechos; sin embago, a lo largo del texto constitucional es posible identificar al menos once dispositivos que protegen específica y directamente a esas personas. Es importante resaltar, por otro lado, que 
uno de los fundamentos de la República Federativa de Brasil es, entre otros, la dignidad de la persona humana (artículo 1). Además, uno de los objetivos fundamentales de la República es «promover el bien de todos sin prejuicios de origen, raza, sexo, color, edad y cualquier otra forma de discriminación» (artículo 3, IV). Por lo tanto, se entiende que la Constitución de 1988 se refiere a la inclusión de todos en la vida en sociedad, lo que se confirma, incluso, a través del principio de igualdad (artículo 5, caput), incluyendo también a las personas con discapacidades. Por lo tanto, tal preocupación no se limita a los artículos específicos, sino que circunda toda la estructura de la Constitución, aunque para la realidad fáctica los avances han sido más lentos.

Es posible citar los artículos 7, XXXI; 23, II; 24, XIV; 37, VIII; 40, § 1, I y $\S 4$, I; $100, \S 2 ; 201$, I y $\S 1 ; 203$, IV y V; 208, III; 227, § 1, II y $\S 2$, y 244, todos de la Constitución de 1988, así como el artículo 102, del Acto de las Disposiciones Constitucionales Transitorias (ADCT), como dispositivos de protección directa a las personas con discapacidad. En ellos se encuentran diversas garantías, así como la búsqueda de la inclusión de las personas con discapacidad en igualdad de condiciones con respecto a las demás personas en el contexto social, estableciendo también deberes de los entes federativos con relación a la protección de tales derechos, y determinando que nuevas leyes dispongan más detalladamente sobre determinadas cuestiones.

Así, después de la Constitución de 1988, surgieron muchas leyes infraconstitucionales acerca de la protección de las personas con discapacidad. Esta vasta legislación abarca diversas áreas como el trabajo, la educación, la salud, la previsión y la asistencia social, los beneficios fiscales y otros; todo ello con el objetivo primordial de la inclusión de las personas con discapacidad, posibilitando el ejercicio de la ciudadanía de forma igualitaria con respecto a las demás personas, buscando así la adecuación de los hechos sociales a los principios constitucionales proclamados. Además, la enmienda constitucional 45, de 08/12/2004, al añadir el $\S 3$ al artículo 5 de la Constitución de 1988, permitió al Congreso Nacional la incorporación de tratados y convenciones internacionales sobre derechos humanos con estatus de enmiendas constitucionales, por medio de su aprobación siguiendo el mismo procedimiento de las enmiendas. Este procedemiento implica el paso por cada casa del Congreso Nacional, en dos turnos y con tres quintos de los votos de sus miembros. Así, en 2008, por decreto legislativo, y en 2009, por decreto de la Presidencia de la República, fueron aprobados, por medio de este proceso, la Convención sobre Derechos de las Personas con Discapacidad y su Protocolo Facultativo, pasando por tanto a tener fuerza constitucional en el ordenamiento jurídico (Nishiyama \& Texeira, 2016). 
Por último, en 2015, fue promulgado el Estatuto de la Persona con Discapacidad (ley 13.146/2015), el cual regula la referida Convención y su Protocolo Facultativo. Este documento consolida toda la legislación anteriormente creada, para abordar específicamente asuntos esenciales para la protección de las personas con discapacidad.

En este sentido, diversos artículos del Código Civil fueron alterados - los principales de ellos relacionados con la capacidad civil de la persona con discapacidad —. Así, actualmente, la simple discapacidad, física o mental, no acarrea incapacidad para el ejercicio de cualquier acto de la vida civil, lo que se confirma por el rol ejemplificativo del artículo 6 de la Ley Brasilera de Inclusión de la Persona con Discapacidad, la cual dispone que la discapacidad no afecta a la plena capacidad civil de la persona.

Además, la nueva ley trajo un enfoque más moderno acerca de la protección conferida a las personas con discapacidad: a saber, la idea de que su dignidad debe ser tutelada por la libertad a ellas atribuida y, aún más, de que la libertad solo puede alcanzarse si la sociedad ofrece condiciones adecuadas de inclusión, por medio de la eliminación de las barreras impuestas que dificultan la participación efectiva (Menezes, Menezes \& Menezes, 2016).

\section{LA ACCESIBILIDAD COMO DERECHO DE LA PERSONALIDAD} Por medio del mencionado presupuesto de la plena capacidad civil, el Estatuto pretende conferir a las personas con discapacidad una vida digna. El nuevo concepto de discapacidad propuesto extrapola los límites de las condiciones personales y pasa a determinarse sobre la base del agravamiento de las limitaciones naturales debido a las barreras sociales. En este sentido, corresponde a la sociedad reformarse con el objetivo de reducir tales barreras y proporcionar la plena participación de la persona en la sociedad (Menezes, Menezes \& Menezes, 2016).

Sobre este nuevo concepto de persona con discapacidad, el artículo 2 del Estatuto dispone, repitiendo lo que ya estaba previsto en la Convención de las Naciones Unidas sobre los Derechos de las Personas con Discapacidad, lo siguiente:

Artículo $2^{\underline{o}}$ Se considera persona con discapacidad aquella que tiene impedimento a largo plazo de naturaleza física, mental, intelectual o sensorial, el cual, en interacción con una o más barreras, puede obstruir su participación plena y efectiva en la sociedad en igualdad de condiciones con las demás personas.

Se trata, por lo tanto, de un concepto relacional. Es decir, la discapacidad no existe por sí sola, surge a partir de la interacción de los atributos 
específicos de la persona con las barreras del medio, lo que dificulta o impide el acceso y el ejercicio de derechos (Ferraz \& Leite, 20 de agosto de 2015).

Esta inclusión solo se hace posible por medio de la accesibilidad, siendo ésta también responsable de conferir una vida digna a las personas con discapacidad. Por eso, la accesibilidad debe ser considerada un derecho de la personalidad. A continuación, ofrecemos un breve análisis acerca de ese instituto jurídico, a fin de comprender lo que se afirma.

Los derechos de la personalidad, en la visión de Alexandre C. Fernandes (2012, p. 192), son derechos relativos a la tutela de la persona humana, considerados esenciales a su dignidad e integridad. Afirma, además, que son facultades ejercitadas naturalmente por la persona, siendo atributos de la condición humana. Sobre la dignidad humana, A. Schreiber (2011, p. 8) elabora el siguiente concepto: «la dignidad humana es el valor-síntesis que reúne las esferas esenciales de desarrollo y realización de la persona humana».

Como se ha explicado anteriormente, la dignidad humana se configura como fundamento de la República Federativa de Brasil (artículo 1, III, de la $\mathrm{CF}$ ). Por lo tanto, su protección puede ser percibida en diversas ramas del derecho brasilero, sea en el ramo público -ámbito de los derechos fundamentales, previstos constitucionalmente-, sea en los derechos de la personalidad - previstos en el Código Civil—. Se observa que el rol previsto en el Código Civil no debilita el objetivo de los derechos de la personalidad, es decir, la protección integral de la persona en todos sus aspectos biopsicológicos. Por eso, autores como Cristiano C. de Farias y Nelson Rosenvald (2007, p. 116) afirman que existe una cláusula general de protección de la personalidad, la cual tiene como presupuesto lógico el artículo 1, III, de la Constitución de 1988, es decir, la dignidad de la persona humana. Francisco Amaral (2008, p. 292) sigue la misma línea al afirmar que el respeto a la persona humana es el marco jurídico básico que justifica la existencia y admite la especificación de los demás derechos.

En el presente ensayo seguimos esta línea de pensamiento, ya que, si el objetivo de los derechos de la personalidad es la protección de la persona de forma integral, no sería posible considerar la existencia de una lista taxativa de derechos, pues la constante evolución de la sociedad, en las nuevas situaciones cotidianas, hace surgir la necesidad de protección de aspectos no abordados por el texto legal y, muchas veces, ni siquiera imaginables en otros tiempos. En este sentido, a pesar de que el texto legal se limita a tratar solo cinco derechos de la personalidad — derecho al cuerpo, derecho al nombre, derecho al honor, derecho a la imagen y derecho a la privacidad - , no es posible excluir de la protección del ordenamiento jurídico otros derechos inherentes a la personalidad, en razón de dicha cláusula general inagotable (Schreiber, 2011, p. 15).

LA ACCESIBILIDAD COMO UN NUEVO DERECHO DE LA PERSONALIDAD EN BRASIL: EL ESTATUTO DE LA PERSONA CON DISCAPACIDAD (LEY 13.146/2015) Y EL DAÑO MORAL QUE SURGE DE LA INACCESIBILIDAD

ACCESSIBILITY AS A NEW PERSONALITY RIGHT IN BRAZIL: THE DISABLED PERSON STATUTE (LAW 13.146/2015) AND THE MORAL DAMAGE ARISING FROM INACCESSIBILITY 
Así, si el objetivo de los derechos de la personalidad es la protección de la dignidad de la persona humana por medio de la tutela de todos sus aspectos, es fácil percibir que otros derechos, aunque no estén previstos en el Código Civil de 2002, pueden ser incluidos como derechos de la personalidad. Para ello, basta que tales derechos sean necesarios con respecto a la condición humana, es decir, deben ser atributos de la personalidad.

En este sentido, se presenta a continuación el análisis detenido del derecho a la accesibilidad previsto en la ley 13.146/2015, para comprender el motivo por el que se afirma, en el presente artículo, que este es un derecho de la personalidad.

Es importante resaltar, inicialmente, que la accesibilidad ya estaba prevista en las leyes $10.048 / 2000$ y $10.098 / 2000$, ambas reguladas por el decreto 5.296/2004. La primera incluye disposiciones sobre la prioridad de atención de las personas con discapacidad y movilidad reducida, mientras que la segunda trata específicamente sobre la accesibilidad. En este contexto, el Estatuto de la Persona con Discapacidad surgió como una forma de unificar tales normas y hacerlas concordar con la Convención de las Naciones Unidas sobre los Derechos de las Personas con Discapacidad, trayendo algunas alteraciones de nomenclaturas y conceptos. Ello se verifica en la nueva redacción dada al artículo 2, I, de la ley 10.098/2000 por el artículo 3, I, de la ley 13.146/2015 sobre el actual concepto de accesibilidad:

Art. 3ํㅡ A los fines de aplicación de esta ley, se considerarán:

I.- accesibilidad: posibilidad y condición de alcance para uso, con seguridad y autonomía, de espacios, mobiliario, equipamientos urbanos, edificaciones, transportes, información y comunicación, incluyendo sus sistemas y tecnologías, así como de otros servicios e instalaciones abiertos al público, de uso público o privado de uso colectivo, tanto en la zona urbana como en la rural, por persona con discapacidad o con movilidad reducida.

La interpretación de este dispositivo, en consonancia con el ya citado concepto de persona con discapacidad, lleva a la siguiente idea:

Los impedimentos físicos, sensoriales, mentales e intelectuales no producen obstáculos por sí solos, sino que estas barreras que impiden el ejercicio de derechos se producen socialmente, siendo fundamentales estrategias políticas, jurídicas y sociales que excluyan esos obstáculos y discriminaciones negativas, permitiendo a los discapacitados demostrar sus capacidades y gozar de autonomía e independencia para una verdadera inclusión social (Araujo \& Costa Filho, 2015, p. 65). 
La exclusión de las barreras producidas socialmente se da a través de, entre otros factores, la accesibilidad. Esta no busca solo la inclusión de las personas con discapacidad, sino también de aquellas con «movilidad reducida», incluyendo ancianos, obesos, gestantes, lactantes y personas acompañadas de niños pequeños (artículo 3, IX, de la ley 13.146/2015).

En este sentido, el Estatuto de la Persona con Discapacidad dispone, inicialmente, que el Estado, la sociedad y la familia aseguran a la persona con discapacidad la efectividad de todos los derechos derivados de la Constitución, incluyendo entre ellos la accesibilidad (artículo 8, ley 13.146/2015). Sin embargo, el Estatuto no se limita a exponer esa norma, sino que le concede contornos más claros, al disponer sobre cada derecho fundamental y el modo por el cual cada uno deberá ser realizado. Más aún, se utiliza un título entero de la ley en comentada para discurrir acerca de la accesibilidad en todas sus versiones, ya que, en lo que se refiere a los derechos fundamentales, la simple lectura de los dispositivos genera la conclusión de que sin accesibilidad no sería posible su concreción.

Además, se percibe que la ley no solo estableció garantías a las personas con discapacidad en el plano formal, sino que también instituyó normas, imponiendo obligaciones tanto para el Estado como para personas físicas y jurídicas. Además, la ley trae nuevos elementos para exigir con mayor rigor el cumplimiento de las mismas en el plano de los hechos.

En particular, la accesibilidad no ha modificado los plazos ya vencidos para la adaptación y adecuación de los edificios públicos y privados de uso colectivo, así como de las calles, plazas, aceras y sitios electrónicos en internet, ya previstos en las leyes $10.098 / 2000$ y $10.048 / 2000$ y el decreto 5296/2004. Sin embargo, las nuevas financiaciones, licitaciones y contratos pasaron a estar condicionados al cumplimiento de los requisitos del diseño universal (Araujo \& Costa Filho, 2015).

Sobre el diseño universal, el artículo 3, II, del Estatuto dispone lo siguiente:

II.- diseño universal: diseño de productos, ambientes, programas y servicios a ser utilizados por todas las personas, sin necesidad de adaptación o de proyecto específico, incluyendo los recursos de tecnología de asistencia.

Además, el título III del Estatuto de la Persona con Discapacidad incluye deberes impuestos, también, al Poder Público, a fin de garantizar el cumplimiento de los requisitos de accesibilidad en las obras públicas y privadas de uso colectivo, así como en el transporte público y los sitios electrónicos. Así, se hace clara la mayor responsabilidad del Estado en lo que se refiere a la efectividad de los derechos de las personas con 
discapacidad y movilidad reducida con respecto a su locomoción, su acceso a la información y su comunicación y participación en la vida pública y política.

Una importante innovación en esta área fue la alteración del artículo 11, IX, de la ley 8.429/1992, la cual pasó a considerar acto de improbidad administrativa que atenta contra los principios de la administración pública «dejar de cumplir la exigencia de requisitos de accesibilidad previstos en la legislación». Es decir, cualquier acción u omisión del Estado que suponga la no efectividad de la garantía de accesibilidad para las personas con discapacidad es, actualmente, un acto de improbidad, lo que refuerza la idea del documento legal de garantizar que dichos derechos no se restrinjan al plano formal (Araujo \& Costa Filho, 2015).

Sin embargo, no fue la única novedad en ese sentido. En efecto, también se realizaron cambios en la Ley de Licitaciones (ley 8.666/93), a fin de exigir el cumplimiento de las normas de accesibilidad. En ese sentido, se estableció la obligación de la administración de fiscalizar el cumplimiento de los requisitos de accesibilidad en los servicios y en los ambientes de trabajo (artículo 66-A, párrafo único), además de otras obligaciones. Por otro lado, se percibe que tales obligaciones no están solamente dirigidas a la administración. El artículo 58, por ejemplo, determina que las constructoras y promotoras inmobiliarias, al realizar la construcción de una edificación multifamiliar, deberán tener en cuenta los requisitos de accesibilidad. Asimismo, deberán garantizar un porcentaje mínimo de unidades accesibles, prohibiéndose el cobro de valores adicionales para la adquisición de esas unidades, confirmando la afirmación de que la ley busca traer a la realidad fáctica los derechos constitucionales e infraconstitucionales que antes existían solo en el texto legal.

El artículo 53 de la ley 13.146/2015, a su vez, prevé la accesibilidad como derecho que garantiza a la persona con discapacidad o con movilidad reducida vivir de forma independiente y ejercer sus derechos de ciudadanía y de participación social. En el esfuerzo de concretar tal derecho, la Asociación Brasilera de Normas Técnicas (ABNT) creó en el año 2015 la NBR 9050 —Norma de Accesibilidad a Edificaciones Muebles, Espacios y Equipamientos Urbanos-, la cual tiene por finalidad establecer parámetros y criterios técnicos a ser observados en la elaboración de proyectos, en las construcciones, instalaciones y adaptaciones de edificaciones, así como en los muebles, espacios y equipamientos urbanos. El objetivo es que ofrezcan condiciones de accesibilidad. La mencionada norma indica especificaciones que pretenden proporcionar a la mayor cantidad posible de personas -independientemente de su edad, estatura olimitación de movilidadla utilización segura del ambiente o del equipo. Ello confirma la afirmación de que no solo el poder público tiene la responsabilidad 
de garantizar la inclusión de las personas con discapacidad, sino que ese es un deber de toda la sociedad, con el fin de reducir las dificultades enfrentadas por esos individuos.

A pesar de todas las normas y leyes anteriormente mencionadas, si uno observa la realidad de la sociedad brasilera actualmente, se percibe que el ideal deseado está lejos de ser alcanzado con plenitud. Es fácil percibir en nuestras rutinas diarias las dificultades por las que pasan las personas con discapacidad e incluso las que tienen movilidad reducida. Entre estas dificultades, se destacan calzadas desniveladas y sin rampas de acceso a las calles; locales sin la debida reserva de plazas para automóviles, transportes públicos con defectos en los ascensores para personas en sillas de ruedas; así como universidades, escuelas e incluso puestos de salud y hospitales que no disponen de rampas, ascensores y baños accesibles para esas personas. Se observa, además, la falta de empatía y respeto de buena parte de la población que, hasta hoy, no cumple las normas que garantizan los derechos de las personas con discapacidad — como, por ejemplo, cuando se utilizan espacios destinados especialmente a las personas con discapacidad: por ejemplo, las plazas reservadas para automóviles cuyo propietario tenga alguna discapacidad o sea anciano- - Otro ejemplo común es el incumplimiento de las normas de accesibilidad en ambientes privados de uso colectivo, como en condominios residenciales.

Todo esto dificulta y, a veces, impide la vida plena e independiente de las personas con discapacidad, quienes necesitan ayuda para hacer cosas simples como caminar en las calles de la ciudad en la que viven e incluso acceder a su propia residencia. Las dificultades de locomoción y acceso a determinados ambientes, sin embargo, no son las únicas enfrentadas por esa parte de la población. La accesibilidad busca eliminar o reducir todos los tipos de barreras y obstáculos que enfrentan las personas con discapacidad o movilidad reducida. Esto incluye el acceso a la información y la comunicación, así como la participación pública y política de estas personas.

En este sentido, el Estatuto de la Persona con Discapacidad (ley 13.146/2015), en consonancia con la Convención de las Naciones Unidas sobre los Derechos de las Personas con Discapacidad, aborda el concepto de barreras en el artículo 3, IV:

barreras: cualquier obstáculo, actitud o comportamiento que limite o impida la participación social de la persona, así como el goce, la fruición y el ejercicio de sus derechos a la accesibilidad, a la libertad de movimiento y de expresión, a la comunicación, al acceso a la comunicación, la información, la comprensión, la circulación con seguridad, entre otros, clasificadas en:

LA ACCESIBILIDAD COMO UN NUEVO DERECHO DE LA PERSONALIDAD EN BRASIL: EL ESTATUTO DE LA PERSONA CON DISCAPACIDAD (LEY 13.146/2015) Y EL DAÑO MORAL QUE SURGE DE LA INACCESIBILIDAD

ACCESSIBILITY AS A NEW PERSONALITY RIGHT IN BRAZIL: THE DISABLED PERSON STATUTE (LAW 13.146/2015) AND THE MORAL DAMAGE

ARISING FROM INACCESSIBILITY 
a) barreras urbanísticas: las existentes en las vías y en los espacios públicos y privados abiertos al público o de uso colectivo;

b) barreras arquitectónicas: las existentes en los edificios públicos y privados;

c) barreras en el transporte: las existentes en los sistemas y medios de transporte;

d) barreras en las comunicaciones y en la información: cualquier obstáculo, actitud, o comportamiento que dificulte o imposibilite la expresión o recepción de mensajes e información a través de sistemas de comunicación y de tecnología de la información;

e) barreras actitudinales: actitudes o comportamientos que impidan o perjudiquen la participación social de la persona con discapacidad en igualdad de condiciones y oportunidades con las demás personas;

f) barreras tecnológicas: las que dificultan o impiden el acceso de la persona con discapacidad a las tecnologías.

Es posible, además, dividir esas barreras en una clasificación tripartita: 1) barreras de actitud, representadas por el miedo, la ignorancia y las bajas expectativas; 2) barreras del medio, resultantes de la inaccesibilidad física presente en el entorno; y 3) barreras institucionales, que son las discriminaciones dotadas de amparo legal, justificando que se excluya a las personas con discapacidad de algunos derechos (Menezes, Menezes \& Menezes, 2016).

Por medio de estos conceptos, se confirma la idea de que la accesibilidad es para todas las personas con discapacidad o movilidad reducida - no solo para aquellas con dificultades de locomoción, sino también para individuos con problemas en el habla, visuales, cognitivos, auditivos y todas las demás posibles diferencias que, en contacto con dichas barreras, impidan la vida plena de esas personas-. Esto se debe a que la accesibilidad debe considerarse un concepto amplio, que abarca la eliminación de todos los tipos de barreras antes citadas. Dicha eliminación se da por medio de la adaptación del medio a fin de que sea posible el uso y el acceso por parte de todas las personas, independientemente de cualquier tipo de atributo físico capaz de generar dificultades o impedimentos en el acceso cuando está en contacto con tales barreras.

A fin de ejemplificar cómo tiene lugar, de hecho, la eliminación de las barreras del medio, es posible citar algunos ejemplos de la norma técnica de la ABNT (NBR 9050). Dicha norma brinda indicaciones sobre los elementos de accionamiento y bloqueo de puertas y el alcance manual para personas que utilizan silla de ruedas, sea en lo que se refiere a distancias horizontales o verticales, inclinación de rampas, parámetros auditivos y visuales, entre otros. La ausencia de accesibilidad hace que estos ciudadanos sufran la restricción de numerosos derechos 
—entre ellos, el ejercicio de la propia ciudadanía, lo que en una sociedad democrática resulta inadmisible-. Por supuesto, una vida con tantas restricciones no puede, en modo alguno, ser considerada digna. La falta de respeto a la dignidad humana en esas situaciones es notable y ese es el punto principal discutido en el presente trabajo.

En consonancia con la exposición hecha sobre los derechos de la personalidad, así como con la existencia de una cláusula general de tutela de la personalidad que tiene como presupuesto la dignidad de la persona humana, se comprueba que la accesibilidad es un derecho de la personalidad. Esto es así porque es necesaria para la garantía de la dignidad; asimismo, resulta también esencial para el pleno ejercicio de la personalidad, pues solo por medio de la accesibilidad será posible que la persona con discapacidad o movilidad reducida sea capaz de ejercer todas las facultades inherentes a su personalidad (como la libertad de locomoción, el derecho de información, el derecho a la comunicación y todos los demás derechos fundamentales de la persona humana).

Por todo lo expuesto, resulta evidente la necesidad, para el ordenamiento jurídico, de tutelar la accesibilidad como un derecho de la personalidad, de modo que su violación dé lugar a la debida responsabilización del que la contraría, para compensar los daños causados.

\section{EL DAÑO MORAL COMO CONSECUENCIA DE LA INACCESIBILIDAD}

El concepto de daño moral y de las formas de reparación del mismo sufrió diversas alteraciones con el transcurrir de los años. En lo que se refiere al concepto, Sérgio Cavalieri Filho (2014, p. 106) afirma que hay varias corrientes. Por ejemplo, hay quien afirma que es un concepto negativo, de modo tal que el daño moral sería aquel que no tiene carácter patrimonial. Por otro lado, existe un concepto positivo que configura el daño moral como dolor, vergüenza, sufrimiento, incomodidad, humillación, o sea, «dolor del alma».

Con el advenimiento de la Constitución de 1988, el hombre fue colocado en el centro del ordenamiento jurídico. Así, sus derechos pasaron a ser integralmente tutelados, dándose mayor importancia a los derechos fundamentales y de la personalidad. Con ello, el daño moral pasó a ser considerado en sentido estricto como la violación del derecho a la dignidad, la cual es tratada en el presente como presupuesto básico de los derechos de la personalidad. En esta perspectiva, no se vincula necesariamente a los aspectos - mencionados anteriormente- de sufrimiento, dolor, o cualquier otra reacción psíquica de la víctima, pudiendo haber violación de la dignidad sin que necesariamente haya tales reacciones, así como también resulta posible lo contrario. Por este

LA ACCESIBILIDAD COMO UN NUEVO DERECHO DE LA PERSONALIDAD EN BRASIL: EL ESTATUTO DE LA PERSONA CON DISCAPACIDAD (LEY 13.146/2015) Y EL DAÑO MORAL QUE SURGE DE LA INACCESIBILIDAD

ACCESSIBILITY AS A NEW PERSONALITY RIGHT IN BRAZIL: THE DISABLED PERSON STATUTE (LAW 13.146/2015) AND THE MORAL DAMAGE

ARISING FROM INACCESSIBILITY 
motivo, se afirma que la reacción psíquica de la víctima solo puede configurar daño moral cuando está relacionada con una agresión a su dignidad (Cavalieri Filho, 2014, p 107). En la misma línea, según María Celina B. de Moraes, «[l] os individuos son titulares de derechos personalísimos que integran su personalidad y no tienen ninguna connotación económica. Los daños a esos derechos fueron llamados morales, pues alcanzan atributos valorativos, o virtudes, de la persona como ente social, o sea, integrada a la sociedad» (2003, p. 155).

Por otra parte, discutir la reparación del daño moral supone ingresar a una cuestión igualmente compleja, ya que, por ser un daño fuera de balance, por mucho tiempo se defendió la idea de que su reparación no podría tener lugar por medio de una indemnización pecuniaria (Moraes, 2003, p. 145). Tal noción ha sido alterada a partir de la idea de que, por más que sea difícil medir la extensión del daño moral al punto de compensarla con una indemnización pecuniaria, es inaceptable pensar que una injusticia practicada por alguien violando derechos de otro pueda ser ignorada en la esfera jurídica. Así, el daño moral pasó a ser compensado pecuniariamente. En la visión de María Celina B. de Moraes, no es el dolor el que está siendo pagado, sino la víctima lesionada en su esfera extrapatrimonial que debería ser recompensada para así disfrutar de otros estados de bienestar psicofísico, a fin de ponderar los efectos que el daño había causado en su espíritu (2003, p. 147). Tal perspectiva se vio consolidada por la Constitución de 1988, cuando en su artículo 5, V y X, expresamente, afirmó la posibilidad de indemnización derivada del daño moral.

Las situaciones que conducen al daño moral, por lo tanto, se basan principalmente en la violación a la dignidad humana, así como en el sufrimiento causado a la víctima, sin que ello sea, sin embargo, un presupuesto necesario para la existencia del daño. Así, se concluye que, con el paso del tiempo, hubo un incremento en las hipótesis de causación de daños, de modo que situaciones dañinas antes ignoradas pasaron a ser hoy tuteladas sobre la base del principio de la dignidad humana (Moraes, 2003, p. 150). Entre estas nuevas causas que dan lugar al daño moral es posible incluir la violación al derecho de accesibilidad. En efecto, la inaccesibilidad afecta a la persona con discapacidad o movilidad reducida en su esfera personal, de modo que hace imposible que ejerza su ciudadanía, así como los derechos básicos de una vida plena en sociedad, como ya fue explicado anteriormente.

Además, la accesibilidad, con el advenimiento de la nueva Ley Brasilera de Inclusión, pasó a ser tratada como derecho de la personalidad, y el daño moral no es más que la violación de los derechos de la personalidad, $\mathrm{o}$, en sentido estricto, de la dignidad de la persona humana. En este sentido, cuando se habla de violación del derecho a la accesibilidad 
se hace evidente la violación de la dignidad humana, ya que, sin accesibilidad, las personas con discapacidad o movilidad reducida se vuelven incapaces de disfrutar de una vida digna. En efecto, no pueden ejercer sus derechos fundamentales a ser independientes y, aún más, a gozar de la plena inclusión social, lo que solo sería posible respetando el principio constitucional de la igualdad.

Por esta razón, la violación del derecho de accesibilidad debe ser reparada por medio de la indemnización por daño moral. Esta indemnización debe ser evaluada por el juez en el caso concreto, teniendo en cuenta la gravedad del daño frente a las condiciones personales de la víctima (Schereiber, 2011, p. 17). Además, se debe tener en cuenta el principio de que el daño no puede ser fuente de lucro, por lo que la indemnización debe ser suficiente para la reparación del daño, sin dar lugar al enriquecimiento sin causa de la víctima (Cavalieri Filho, 2014, p. 125).

Por último, todo aquel cuyo derecho a la accesibilidad sea violado tiene el derecho de solicitar judicialmente la reparación de los daños morales. Sin embargo, surge la duda relativa al daño moral en general y acerca de cómo se prueba el daño. La existencia del daño moral, en la doctrina y jurisprudencia actual, se justifica por la prueba del hecho lesivo, o sea, el daño moral existe in re ipsa, derivando del propio hecho ofensivo (Cavalieri Filho, 2014, p. 116). Así, en el caso del daño resultante de la inaccesibilidad, basta que se compruebe el hecho lesivo, es decir, la ausencia de accesibilidad que impida el ejercicio de algún derecho de la víctima. No es necesaria, por lo tanto, la comprobación del sufrimiento de la persona, pues el hecho por sí solo ya configura la violación a la dignidad humana de la persona con discapacidad o movilidad reducida. Es decir, el daño moral deriva de la simple violación del derecho a la personalidad, es decir, la accesibilidad.

Es posible notar en la jurisprudencia de los tribunales brasileros que la inaccesibilidad ya estaba siendo tratada como causa capaz de dar lugar a la reparación por daños morales, tomando como base las leyes que ya regulaban algunas normas de accesibilidad, así como la Convención de las Naciones Unidas sobre los Derechos de las Personas con Discapacidad. Ello se desprende, por ejemplo, de la siguiente sentencia:

ACCIÓN DE INDEMNIZACIÓN POR DAÑOS MORALES PERSONA CON DISCAPACIDAD FÍSICA ASIENTO ESPECIAL NO DISPONIBLE. Pretende la anulación de la condena al pago de indemnización por daños morales o su reducción. INADMISIBILIDAD: La empresa aérea no produjo ninguna prueba de la inexistencia de vicio en la prestación del servicio o culpa exclusiva del consumidor o de terceros. La indemnización se fijó en un valor razonable y proporcional. Sentencia mantenida. RECURSO RECHAZADO (TAM v. Marley Maria Tusi Rodriguez).

\section{LA ACCESIBILIDAD COMO UN NUEVO DERECHO DE LA PERSONALIDAD EN BRASIL: EL ESTATUTO DE LA PERSONA CON DISCAPACIDAD (LEY 13.146/2015) Y EL DAÑO MORAL QUE SURGE DE LA INACCESIBILIDAD}

ACCESSIBILITY AS A NEW PERSONALITY RIGHT IN BRAZIL: THE DISABLED PERSON STATUTE (LAW 13.146/2015) AND THE MORAL DAMAGE ARISING FROM INACCESSIBILITY 
El Estatuto de la Persona con Discapacidad consolidó aún más esta idea al abordar la accesibilidad como un derecho de la personalidad. Así, no quedan más dudas sobre la necesidad de reparación del daño moral causado por la inaccesibilidad. En este sentido, las sentencias más recientes también determinan la indemnización:

APELACIÓN [AGRAVO] INTERNA EN LA APELACIÓN [AGRAVO] EN RECURSO ESPECIAL. DERECHO DEL CONSU. MIDOR Y PROCEDIMIENTO CIVIL (CPC/73). DISCAPACIDAD FÍSICA (ENANISMO). IMPOSIBILIDAD DE ACCESO AL APARATO DE VALIDACIÓN DEL SISTEMA DE BILLETAJE ELECTRÓNICO.

$[\ldots]$

5.- MONTO COMPENSATORIO FIJADO A TÍTULO DE DAÑOS MORALES. ART. 944 CC. Razonabilidad. ADECUACIÓN ALCASO CONCRETO. IMPOSIBILIDAD DE REDUCCIÓN. INFORME 07/ STJ.

\section{6.- DECISIÓN JURISPRUDENCIAL. NO COMPROBACIÓN.}

7.- APELACIÓN [AGRAVO] RECHAZADO (Viação Rubanil Ltd. v. Viviane Alves de Assis).

Recurso especial. Acción civil pública. Acción destinada a imponer a la institución financiera demandada la obligación de adoptar el método braille en los contratos bancarios de adhesión celebrados con personas con discapacidad visual.

1. Formación de litisconsorcio pasivo necesario. Inadecuación, en la hipótesis.

2. Deber legítimo consistente en la utilización del método braille en las relaciones contractuales bancarias establecidas con consumidores con discapacidad visual. Existencia. Normatividad con base constitucional y legal. La observancia. Necesidad.

3. Condena por daños fuera de balance colectivos. Conveniencia.

4. Imposición de multa diaria por el incumplimiento de las determinaciones judiciales. Revisión del valor fijado. Necesidad, en la especie.

5. Efectos de la sentencia registrada en el seno de la acción civil pública destinada a la tutela de intereses colectivos stricto sensu. Decisión que surte efectos en relación con todos los consumidores con discapacidad visual que establezcan o tengan una relación contractual con la institución financiera demandada en todo el territorio nacional. Indivisibilidad del derecho tutelado. Art. 16 de la ley 7.347/1985. Inaplicabilidad, en la especie. Los precedentes. 7. Recurso especial parcialmente provisto (Associação Fluminense de Amparo aos Cegos-AFAC v. Banco do Brasil). 
Por todo lo expuesto, se nota que los tribunales cumplen una función esencial para hacer efectivo el derecho a la accesibilidad, ya que, además de que resulta posible solicitar la indemnización por daños morales, también es posible exigir el cumplimiento de las normas de accesibilidad.

Por último, hace falta analizar quién deberá ser demandado en las acciones que buscan la reparación por daños morales.

\section{EL RESPONSABLE DE LA INDEMNIZACIÓN}

El Estatuto de la Persona con Discapacidad y las demás normas sobre accesibilidad delimitan la responsabilidad por la promoción de la accesibilidad de acuerdo con cada caso concreto. Hay, en el artículo 8 de la ley 13.146/2015, una norma general sobre el deber de promover los derechos de las personas con discapacidad, incluyendo entre ellos la accesibilidad:

Artículo $8^{\circ}$ Es deber del Estado, de la sociedad y de la familia asegurar a la persona con discapacidad, con prioridad, la efectividad de los derechos referentes a la vida, a la salud, a la sexualidad, a la paternidad y a la maternidad, a la alimentación, a la vivienda, a la educación, a la profesionalización, al trabajo, a la previsión social, a la habilitación y a la rehabilitación, al transporte, a la accesibilidad, a la cultura, al deporte, al turismo, al ocio, a la información, a la comunicación, a los avances científicos y tecnológicos, a la dignidad, al respeto, a la libertad, a la convivencia familiar y comunitaria, entre otros derivados de la Constitución Federal, de la Convención sobre los Derechos de las Personas con Discapacidad y su Protocolo Facultativo y de las leyes y de otras normas que garanticen su bienestar personal, social y económico.

Se observa, a partir de la lectura del dispositivo, que la accesibilidad y todos los demás derechos de las personas con discapacidad o movilidad reducida son de responsabilidad de toda la sociedad. Por ese motivo, es posible afirmar que se hace necesario analizar cada caso concreto para solamente entonces concluir de quién será la responsabilidad por indemnizar el daño moral resultante de la inaccesibilidad.

Es importante subrayar la posición de Sérgio Cavalieri Filho (2014, p. 14): para este autor, la violación de un deber jurídico caracteriza al ilícito, el cual a su vez tiene como consecuencia, por regla general, el daño a alguien, generando un nuevo deber jurídico, a saber, el de reparar el daño. Es en ese sentido que surge el concepto de responsabilidad civil, que consiste justamente en ese deber de reparar un daño causado por el incumplimiento de un deber jurídico. Tal concepción se confirma por la redacción del artículo 186 del Código Civil de 2002 — «l que, por acción u omisión voluntaria, negligencia o imprudencia, viola derecho y causa daño a otro, aunque exclusivamente moral, comete acto

LA ACCESIBILIDAD

COMO UN NUEVO

DERECHO DE LA

PERSONALIDAD

EN BRASIL: EL

ESTATUTO DE LA

PERSONA CON

DISCAPACIDAD

(LEY 13.146/2015)

Y EL DAÑO MORAL

QUE SURGE DE LA

INACCESIBILIDAD

ACCESSIBILITY AS A NEW PERSONALITY

RIGHT IN BRAZIL:

THE DISABLED

PERSON STATUTE

(LAW 13.146/2015)

AND THE MORAL

DAMAGE

ARISING FROM

INACCESSIBILITY 
ilícito»—, así como por el artículo 927 del mismo documento legal, el cual dispone que «aquel que, por acto ilícito, cause daño a otro, queda obligado a repararlo».

Así, en la concepción del mismo autor (Cavalieri Filho, 2014, p. 17), siempre que se pretenda identificar quién es el responsable civil, será necesario saber quién violó el deber jurídico preexistente, ya que se trata de un deber sucesivo. Excepcionalmente, será posible identificar la responsabilidad indirecta, por la acción de otros — como, por ejemplo, en el caso del fiador-, pero ese no es el enfoque del presente estudio.

En lo que se refiere a la identificación del responsable del pago de la indemnización compensatoria, no se vislumbran grandes dificultades. En efecto, las normas de accesibilidad previstas en el Estatuto de la Persona con Discapacidad y en las demás leyes que tratan de ese asunto establecen específicamente la responsabilidad en cada situación concreta. A fin de contribuir a esta discusión, se puede sistematizar de la siguiente manera la atribución de responsabilidad, con base en el artículo 8 del Estatuto de la Persona con Discapacidad (ley 13.146/2015):

\begin{tabular}{|l|l|}
\hline \multicolumn{1}{|c|}{ RESPONSABLE } & \multicolumn{1}{c|}{ SITUACIÓN } \\
\hline $\begin{array}{l}\text { Entes de la Administración Pública } \\
\begin{array}{l}\text { Directa (Unión, Estados, Distritos Fe- } \\
\text { derales y Municipios) }\end{array}\end{array}$ & $\begin{array}{l}\text { En vías públicas (calles, plazas, carrete- } \\
\text { ras) y reparticiones de la administración } \\
\text { directa }\end{array}$ \\
\hline $\begin{array}{l}\text { Entes de la Administración Pública } \\
\text { Indirecta (Autarquías, Fundaciones, } \\
\text { Empresas Públicas, Sociedades de Eco- } \\
\text { nomía Mixta) }\end{array}$ & $\begin{array}{l}\text { En sus reparticiones y espacios de su } \\
\text { responsabilidad. }\end{array}$ \\
\hline $\begin{array}{l}\text { Sociedad en general } \\
\text { Familia }\end{array}$ & $\begin{array}{l}\text { En bienes particulares de uso colectivo, } \\
\text { como comercio, establecimientos de } \\
\text { prestación de servicios, condominios } \\
\text { edilicios, empresas, etcétera, ya que en } \\
\text { ese caso no se aplica la posibilidad de } \\
\text { right to refuse the service (derecho de re- } \\
\text { chazar el servicio al usuario) }\end{array}$ \\
\hline En el hogar, en la residencia
\end{tabular}

A fin de configurar la responsabilidad civil, la doctrina y la jurisprudencia señalan tres supuestos esenciales: 1) hecho antijurídico imputable a alguien; 2) daño; 3) nexo de causalidad (Noronha, 2010, p. 492).

Para insertar tales supuestos en el tema comentado, es posible considerar que el hecho antijurídico es el incumplimiento de las normas de 
accesibilidad, o sea, una conducta de omisión de determinado agente. El daño, a su vez, es el daño moral, la ofensa a la personalidad del individuo o, en las palabras de Rolim (2016), la ofensa capaz de repercutir en lo que es más esencial al ser humano, la vida y la dignidad. Por último, el nexo de causalidad es algo así como el eslabón entre el hecho generador y el daño (Noronha, 2010, p. 499) y será comprobado en el caso concreto cuando la ausencia de accesibilidad impida o dificulte el ejercicio de determinado derecho del individuo con discapacidad.

El artículo 56, § 2 de la mencionada ley, por ejemplo, dispone que el poder público es responsable de la aprobación, licenciamiento o emisión de certificados de proyectos ejecutivos arquitectónicos, urbanísticos y de instalaciones y equipos temporales o permanentes, debiendo asegurarse del cumplimiento de las reglas de accesibilidad. Por otro lado, el artículo 58 de la ley 13.146/2015 establece que las constructoras privadas multifamiliares deben ajustarse a los preceptos de accesibilidad, debiendo asegurar, incluso, un porcentaje mínimo de unidades internamente accesibles, prohibiéndose la cobranza de valores adicionales para la adquisición de las mismas. Así, el responsable de la compensación del daño moral resultante de la inaccesibilidad deberá ser identificado de acuerdo con las normas que determinan la responsabilidad por la promoción de la accesibilidad.

Con el fin de ejemplificar lo explicitado, se añade la siguiente sentencia:

APELACIÓN [AGRAVO] DE INSTRUMENTO EN RECURSO DE REVISTA DE LOS RECLAMANTES. INDEMNIZACIÓN POR DAÑOS MORALES. FALTA DE ACCESO AL SANITARIO ESPECIAL DE LA EMPRESA POR FUNCIONARIO PORTADOR DE PARAPLEJIA. MONTO INDEMNIZATORIO REDUCIDO A R \$ 15.000,00 (QUINCE MIL REALES). CRITERIOS DE RAZONABILIDAD Y PROPORCIONALIDAD OBSERVADOS (Felipe Diogo Valadão v. Carrefour Comércio e Indústria Ltda).

A pesar de que la sentencia antes citada ha sido dictada por el Tribunal Superior del Trabajo, versa sobre la materia abordada en el presente trabajo, es decir, el daño moral derivado del incumplimiento de las normas de accesibilidad. Por medio de la lectura del texto íntegro de la sentencia se confirma que el empleador, Carrefour Comércio e Indústria Ltda., fue condenado al pago de indemnización por daños morales a un funcionario con discapacidad que no tenía acceso a un sanitario accesible.

Se observa que la fundamentación utilizada por el magistrado en primera instancia para la condena se basa en el incumplimiento de las normas de accesibilidad previstas en la ley 10.098/2000, afirmando lo siguiente: 
En el lugar del establecimiento de la empresa, debería existir el mínimo legal de accesibilidad para los clientes, así como para sus empleados con discapacidad. De esta manera, habiendo contratado a un discapacitado físico como empleado, debería la reclamada conceder medios accesibles y adecuados para mejor condición de vida del autor.

Sin embargo, por las pruebas adjuntas a los autos, observo que no hubo el debido respeto al derecho de accesibilidad a las personas con discapacidades físicas, en particular el reclamante (Felipe Diogo Valadão v. Carrefour Comércio e Indústria Ltda, 9).

Tal posición fue mantenida por el Tribunal Regional, pero con reducción del monto indemnizatorio, por haber sido considerado exorbitante, lo que fue mantenido por el Tribunal Superior del Trabajo.

Se observa, por último, que la rendición de cuentas del empleador es el resultado, justamente, de ser el responsable de proporcionar un número mínimo de baños accesibles en virtud de la ley 10.098/2000. De esa manera, habiendo incumplido su deber legal fue obligado a reparar el daño de ese derivado. Por lo tanto, es posible hablar de responsabilidad de aquellos que no cumplen con la obligación de garantizar la accesibilidad de las personas con discapacidad, ya que tal omisión perjudica el ejercicio de muchos derechos de la personalidad fundamentales de esas personas, quienes necesitan una atención especial para ejercer plenamente su dignidad.

\section{CONCLUSIÓN}

La transformación legislativa y social, en lo que se refiere al tratamiento que se brinda a las personas con discapacidad en Brasil y en el mundo, ha sufrido una significativa evolución. Hoy, esos individuos ya no son vistos como incapaces o como personas que tienen simplemente limitaciones propias y exclusivamente analizadas por medio de conceptos médicos. Las deficiencias pasaron a ser consideradas como dificultades impuestas por el medio en el que la persona vive en contacto con características propias de aquel individuo. En ese sentido, ya no se habla de una necesidad de exclusión del medio social de la persona con discapacidad, sino que, por el contrario, se busca cada vez más la adaptación del medio a la persona, para que ella pueda tener una vida con plena inclusión y participación social.

En este sentido, la accesibilidad surge como derecho esencial de la personalidad humana, ya que permite, justamente, esa tan anhelada inclusión y, además, se constituye en un elemento indispensable para la concreción de dos valores constitucionales esenciales, la igualdad y la dignidad de la persona humana. Además, la accesibilidad puede ser vista como la concreción de la idea de la adaptación del medio a la persona, 
de modo que, independientemente de cualquier especificidad física o mental, todos tengan acceso a los bienes públicos y privados de uso colectivo, así como a la información y, también, a la plena participación pública y política, siendo capaces de ejercer por completo su ciudadanía.

Se percibe que la ley 13.146/2015 buscó garantizar más derechos y nuevas formas de concreción de los mismos, en busca de satisfacer los ideales constitucionales de igualdad y dignidad de la persona humana y, también, con el fin de regularizar la Convención de las Naciones Unidas los Derechos de las Personas con Discapacidad, la cual ya había sido incorporada en el ordenamiento jurídico brasilero con estatus de enmienda constitucional desde 2008.

En el presente estudio, se ha comprobado que la violación del derecho a la accesibilidad genera daño moral, es decir, causa un daño fuera de balance a aquella persona que sufre la vulneración de dicho derecho. Por más que no se pueda comprobar el sufrimiento psíquico o físico de la persona, esta situación dará lugar a la reparación por daños morales, ya que se trata de una nítida violación del derecho a la personalidad y de la propia dignidad de la persona humana. Así, la reparación por daños morales derivada de la inaccesibilidad deberá ocurrir siempre que el acceso o el ejercicio de determinado derecho sea dificultado o impedido en razón del incumplimiento de normas de accesibilidad, pues eso, por sí solo, ya configura el daño moral.

Por todo lo expuesto, puede notarse la importancia de la accesibilidad para la construcción de una sociedad justa e igualitaria, en la que sea posible el pleno ejercicio de la ciudadanía por todos, sin ningún tipo de discriminación. Por último, se sabe que en Brasil todavía hay una gran distancia por recorrer para llegar a la plena concreción de la accesibilidad y de todos los ideales buscados por el Estatuto de la Persona con Discapacidad. Sin embargo, es posible vislumbrar grandes avances en esas áreas, lo que lleva a creer que, en el futuro, será posible vivir en una sociedad cuyas personas con discapacidad no enfrenten las dificultades de inclusión social que aún hoy son experimentadas.

\section{REFERENCIAS}

Amaral, F. (2008). Direito civil: Introdução (7ma ed.). Río de Janeiro: Renovar.

Araujo, L.A.D. \& Costa Filho, W.M. (2015). O estatuto da pessoa com deficiência - EPCD (Lei №. 13.146, de 06.07.2015): algumas novidades. Revista dos Tribunais, 962/2015, 65-80.

Cavalieri Filho, S. (2014). Programa de responsabilidade civil (11ma ed.). São Paulo: Atlas. 
Farias de, C.C. \& Rosenvald, N. (2007). Direito civil: teoria geral (6ta ed.). Río de Janeiro: Lumen Juris.

Fernandes, A.C. (2012). Direito civil. Introdução: pessoas e bens. Caxias do Sul: EDUCS.

Ferraz, C.V. \& Leite, G.S. (20 de agosto de 2015). Lei brasileira de inclusão e o «novo» conceito de deficiência: será que agora vai «pegar»? Justificando. Recuperado de http://justificando.cartacapital.com.br/2015/08/20/lei-brasileirade-inclusao-e-o-novo-conceito-de-deficiencia-sera-que-agora-vai-pegar/

Jaques, K. (s.f.). Direito fundamental à acessibilidade. Recuperado de http:// webcache.googleusercontent.com/search?q= cache:nIsGyUIvEAMJ:www.stf. jus.br/repositorio/cms/portalTvJustica/portalTvJusticaNoticia/anexo/KARINA JAQUES.doc $+\& c d=3 \& h l=$ en\& $\& \mathrm{ct}=\mathrm{clnk} \& \mathrm{gl}=\mathrm{br}$

Nishiyama, A.M. \& Texeira, C.N.(2016). A evolução histórica da proteção das pessoas com deficiência nas constituições brasileiras: os instrumentos normativos atuais para a sua efetivação. Revista de Direito Privado, 68, 225-240.

Menezes de, J.B., Menezes de, H.J.B. \& Menezes de, A.B. (2016). A abordagem da deficiência em face da expansão dos direitos humanos. Revista de Direitos e Garantias Fundamentais, 17(2), 551-572.

Moraes de, M.C.B. (2003). Danos à pessoa humana. Río de Janeiro: Renovar.

Noronha, F. (2010). Direito das obrigações (3ra ed.). São Paulo: Saraiva.

Pereira, R.V. \& Lelis, H.R. (2016). Igualdade e dignidade humana das pessoas portadoras de deficiência: reflexos da nova lei de inclusão -Lei № 13.146/2015no ãmbito da saúde. Revista Brasileira de Direitos e Garantias Fundamentais, 2(1), $19-35$.

Rolim, J.F.S. (2016). A afronta ao direito ao meio ambiente ecologicamente equilibrado (direito geral de personalidade e fundamental) gera ofensa à dignidade e é caso de dano moral à pessoa humana. Tesis presentada para la obtención del título de Doctor en Derecho en la Pontificia Universidad Católica de São Paulo.

Schereiber, A. (2011). Direitos da personalidade. São Paulo: Atlas.

Tartuce, F. (26 de agosto de 2015). Alterações do Código Civil pela Lei № 13.146/2015 (Estatuto da Pessoa com Deficiência). Repercussões para o Direito de Família e Confrontações com o Novo CPC. Parte II. Migalhas. Recuperado de http://www.migalhas.com.br/FamiliaeSucessoes/104,MI225871,51045-Altera coes + do + Codigo + Civil + pela + lei $+131462015+$ Estatuto + da + Pessoa + com

\section{Jurispudencia, normativa y otros documentos legales}

Associação Fluminense de Amparo aos Cegos-AFAC v. Banco do Brasil [Recurso especial], REsp n. ${ }^{\circ} 1315822$ RJ 2012/0059322-0 (3ra Junta, Tribunal Superior de Justicia [Brasil]), 24 de marzo de 2015.

Código Civil [Brasil] (2002)

Constitución de la República Federativa de Brasil (1988). 
Convención de las Naciones Unidas sobre los Derechos de las Personas con Discapacidad, A/RES/61/106. Organización de las Naciones Unidas, 13 de diciembre de 2006.

Decreto 5.296/2004, Decreto que Reglamenta la Ley $10.048 / 2000$ y la Ley 10.098/2000. Diário Oficial da União, 1, 03 de diciembre de 2004, 5.

Felipe Diogo Valadão v. Carrefour Comércio e Indústria Ltda. [Apelación [Agravo] en Recurso de Revista], ARR 817-33.2011.5.15.0003 (2da Junta, Tribunal Superior del Trabajo [Brasil]), 02 de setiembre de 2015.

Ley 8.429/1992, Ley de Improbidad Administrativa. Diário Oficial da União, 03 de junio de 1992, 1, 6993.

Ley 8.666/1993, Ley de Licitaciones y Contratos. Diário Oficial da União, 22 de junio de 1993, 1, 8269 .

Ley 10.048/2000, Ley de Atención Prioritaria. Diário Oficial da União, 1 [versión electrónica], 09 de noviembre de 2000, 1.

Ley 10.098/2000, Ley de Accesibilidad. Diário Oficial da União, 1 [versión electrónica], 20 de diciembre de 2000, 2.

Ley 13.146/2015, Ley Brasilera de Inclusión de la Persona con Discapacidad [Estatuto de la Persona con Discapacidad]. Diário Oficial da União, 1, 07 de julio de 2015, 2.

NBR 9050, Norma Brasileira: Acessibilidade a edificações, mobiliário, espaços e equipamentos urbanos. Associaçao Brasileira de Normas Técnicas (ABNT). Recuperada de http://www.ufpb.br/cia/contents/manuais/abntnbr9050-edicao-2015.pdf

LA ACCESIBILIDAD COMO UN NUEVO

DERECHO DE LA

PERSONALIDAD

EN BRASIL: EL

ESTATUTO DE LA

PERSONA CON

DISCAPACIDAD

(LEY 13.146/2015)

Y EL DAÑO MORAL

QUE SURGE DE LA

INACCESIBILIDAD

ACCESSIBILITY AS A

NEW PERSONALITY

RIGHT IN BRAZIL:

THE DISABLED

PERSON STATUTE

(LAW 13.146/2015)

AND THE MORAL

DAMAGE

ARISING FROM

INACCESSIBILITY

TAMv.MarleyMariaTusiRodriguez [apelación],APLn. ${ }^{\circ} 00353737220128260002$ SP 0035373-72.2012.8.26.0002 (37 Cámara de Derecho Privado, Tribunal de Justicia de São Paulo (Brasil]), 02 de abril de 2013.

Viação Rubanil Ltd. v. Viviane Alves de Assis [Apelación interna [Agravo interno] en recurso especial], AgInt en AREsp n. 914578 RJ 2016/0134550-6 (3ra Junta, Tribunal Superior de Justicia [Brasil]), 09 de marzo de 2017. 